\title{
CREATING BALANCE BETWEEN TRANSFORMATION AND PRESERVATION WITHIN UNESCO WORLD HERITAGE SITES: A CASE STUDY OF BELPER, UK
}

\author{
ASLIHAN CAROUPAPOULLÉ \\ School of Art, Kingston University, London
}

\begin{abstract}
This practice-based research seeks to create a design-led strategy encouraging future development and sustainable design within a UNESCO World Heritage Site. The focus is the town of Belper in the Derwent Valley Mills WHS, an area currently under pressure from diverse and conflicting socioeconomic forces, in need of a coherent regeneration plan. It aims to contribute to such a plan, drawing from theoretical investigations of alternative urbanism and heritage studies, alongside extensive firsthand investigations of Belper and its surrounding industrial landscape as both a heritage site and living community. As an example of the pioneering period of the Industrial Revolution, Belper's identity is defined by its overall form and its relationship to the industrial landscape. It is essential that these relationships are definite and recognisable. However, abandonment of large factory buildings and closure of many warehouses and garages have left behind vast, derelict land and a bizarre landscape that needs to be remediated. Recent proposals take a piecemeal design approach, focusing only on specific problem areas instead of generating an overarching strategy for the development of the town as an extension of Derwent Valley WHS. This research proposes an innovative approach that regards the site as a palimpsest, a concept based on alternative urban theories, which recognises, reinforces, and enhances the distinctive characteristics of the historic environment while upgrading it for the $21 \mathrm{st}$ century. This is achieved through extensive and focused research of the existing layers of the historic built environment and its cultural significance, the natural environment, the social landscape, and the economic forces competing over the above. Knitting together the new and the existing, the researchled design proposal seeks to repair and upgrade Belper's existing urban grain by promoting appropriate and viable mixed-use development to enhance the life of the local community while respecting and recognising the heritage listing and wider countryside setting.

Keywords: UNESCO, heritage, palimpsest, post-industrial, memory, architecture, urban design.
\end{abstract}

\section{INTRODUCTION}

Stretching $24 \mathrm{~km}$ down the river valley from Matlock bath to Derby, the Derwent Valley Mills World Heritage Site contains a series of 18th and 19th century cotton mills with an industrial landscape of high historical and technological significance, which became the key to the birth of the industry. Richard Arkwright's system developed at Cromford adopted throughout the valley, making the Derwent Valley Mills unique in the sense that they became the model for factories throughout the world in following centuries. In the 80-year period from the 18th century, the Derwent Valley witnessed the development of new types of buildings to house revolutionary technology for water-powered manufacturing, driven by the waters of the four principal industrial settlements of Cromford, Belper, Milford, and Darley Abbey articulated by the river Derwent. By 1788 there were over 200 Arkwright type mills in Britain [1].

UNESCO inscribed the Derwent Valley Mills on the World Heritage List in 2001, recognising it as a birthplace of the factory system in the early 19th century. It was here, for the first time, that new types of buildings associated with the large-scale industrial production of cotton were inserted in an otherwise rural environment. The need to provide housing and other facilities for workers and managers resulted in the creation of the first modern industrial 
towns. However, after the pioneering phase, the change from water to steam power in the 19th century moved the focus of the cotton spinning industry up to Lancashire, freezing the main attributes of this remarkable cultural landscape in time, causing "arrested industrialisation".

Belper is the central point of the Derwent Valley Mills World Heritage Site. As a small market town on the River Derwent to the north of Derby, the town has a history dating back to Norman times. Before the Strutts built mills using the waterpower from the River Derwent, Belper was originally known for nail making, the textile industry - began as a cottage industry - as well as potteries and coal quarries. The introduction of cotton mills by Jedediah Strutt, at the beginning of the 19th century, changed its landscape, turning the small village into a large industrial town (Fig. 1). However, the manufacturing tradition of the eighteenth and nineteenth century is now completed, the town must find itself a new significance.

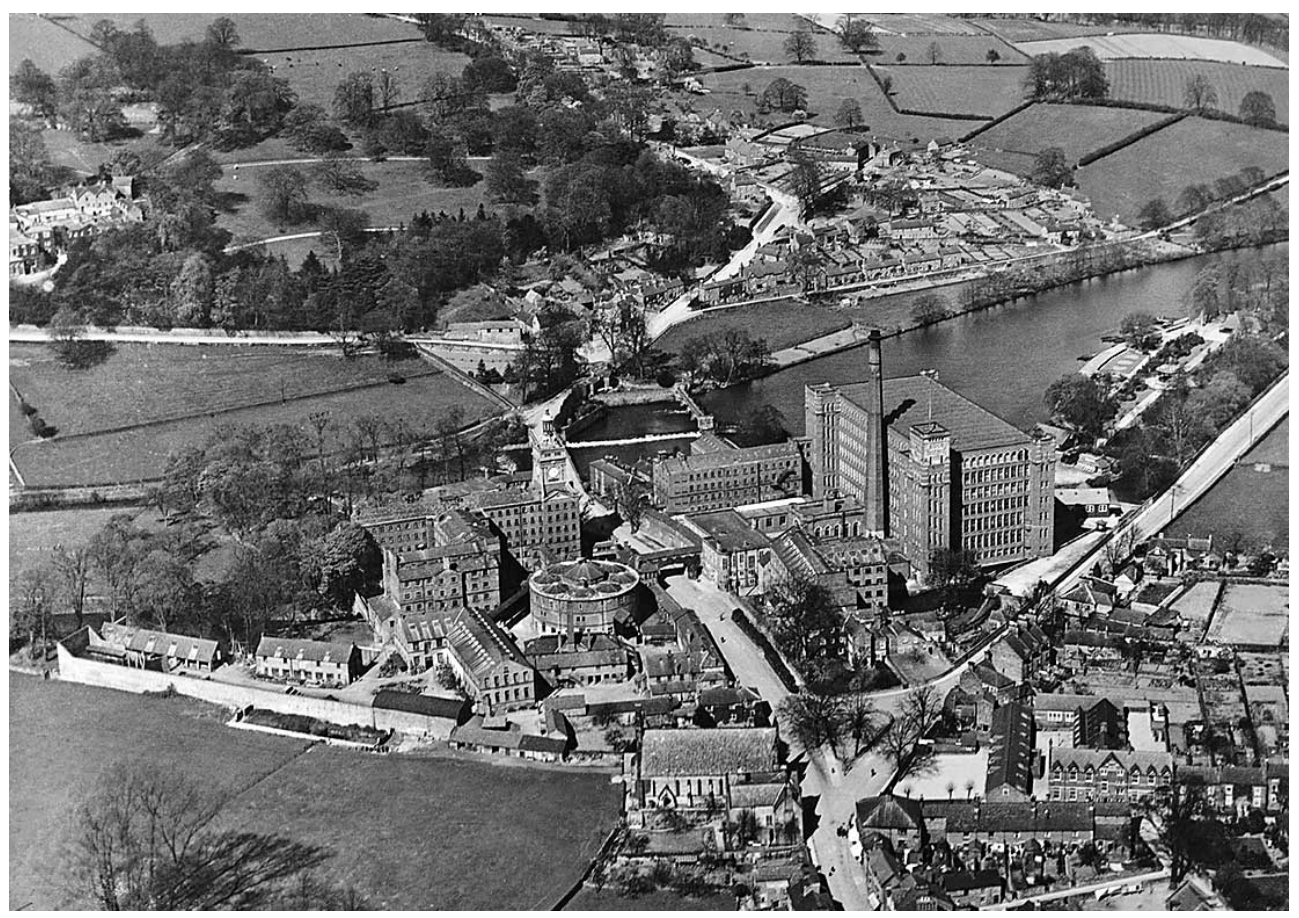

Figure 1: Belper Mills complex. (Source: Historic England, 1931.)

\section{CONTEXT: BELPER AS A PART OF DERWENT VALLEY MILLS WORLD HERITAGE SITE}

Belper is an example of the pioneering period of the Industrial Revolution. The town's identity is defined by its overall form and its relationship to the industrial landscape and the broader agricultural landscape (Fig. 2(a)). It is important that these relationships should be definite and recognisable. However, the post-industrial decline of the town and closure of Thornton's chocolate factory in 1998 has left the town struggling economically while adopting the modern era. Despite the global recognition of the World Heritage Site, little recognition has been given to wider area in Belper. This has resulted in a legacy of brownfield sites and industrial structures in the town centre (Fig. 2(b)). 


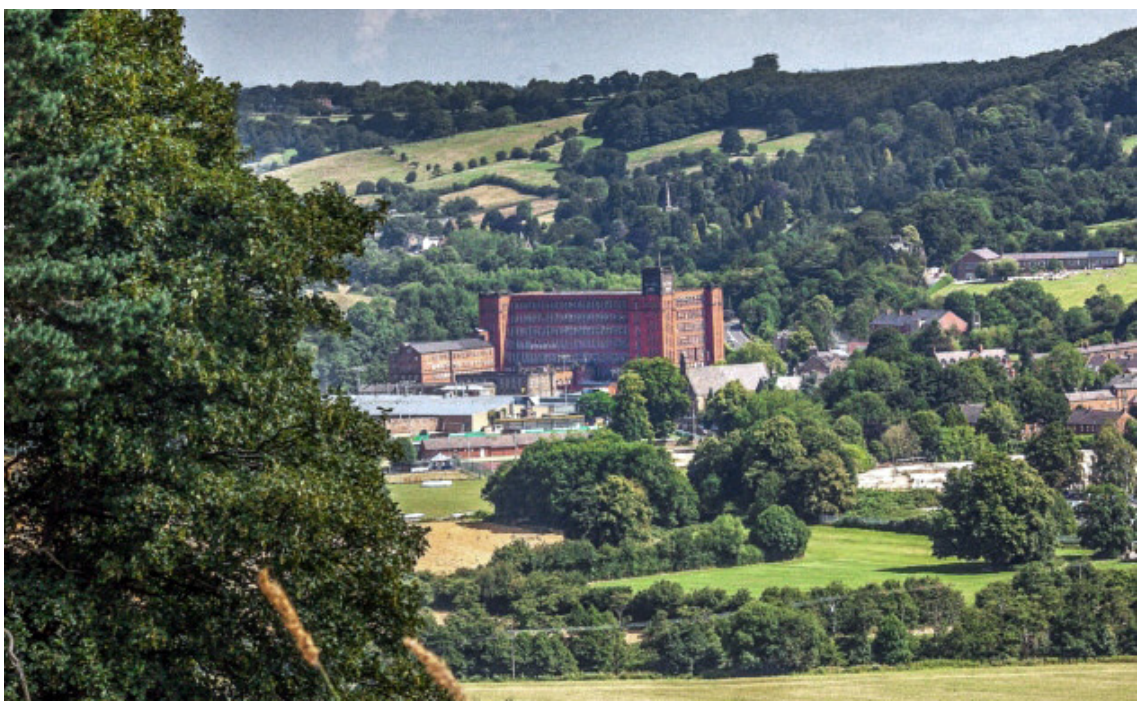

(a)

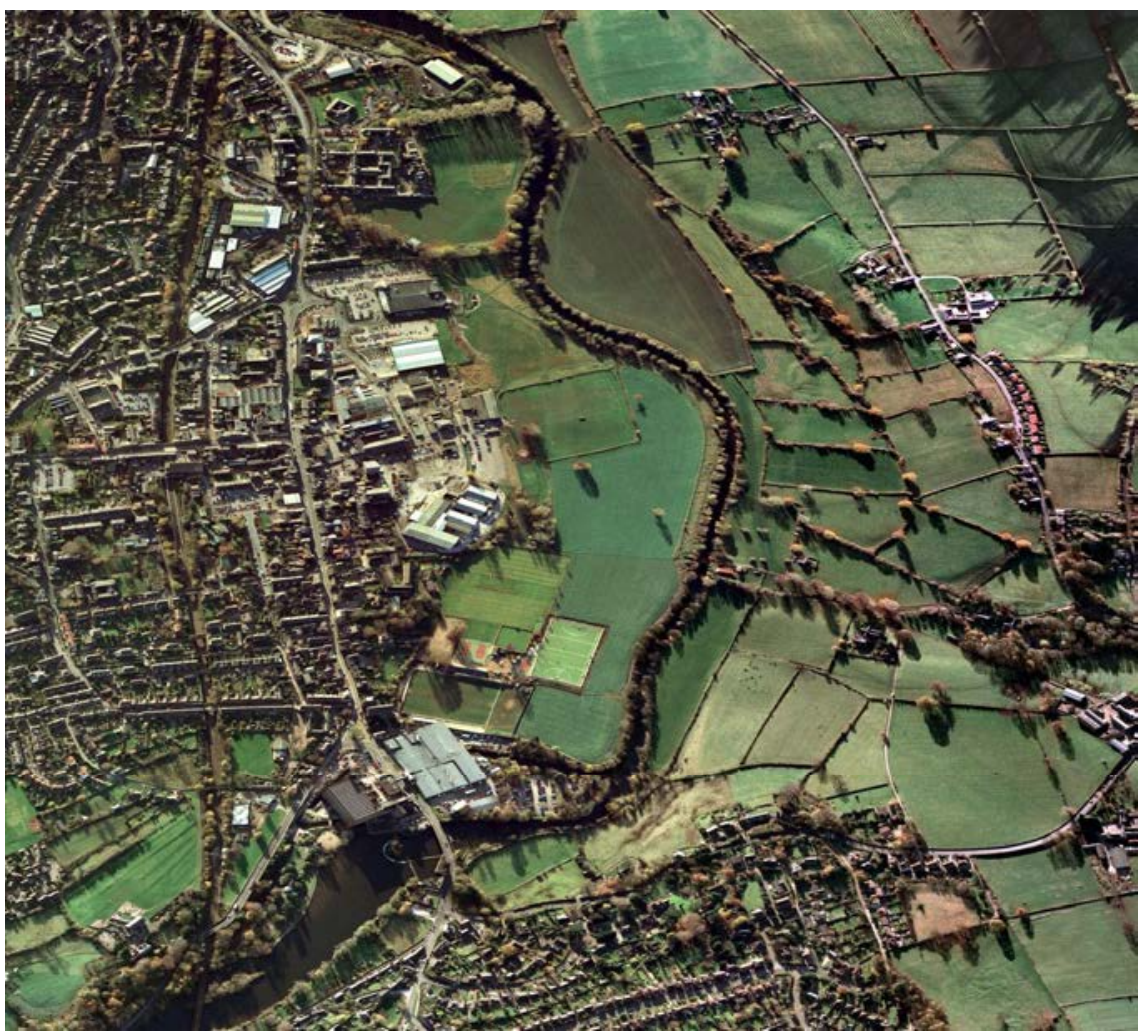

(b)

Figure 2: (a) East Mill and North Mill within the post-industrial landscape of Belper Meadows; and (b) Belper town centre. (Source: Google maps, 2018.) 
In particular, the Meadows sitting between the embankment of the Derwent River and next to the defragmented industrial estate finds itself as a location that the town had almost turned its back on. The neglect and abandonment of the buildings such as the former Thornton's factory complex and the insensitive boundary treatment give an unsightly and unwelcoming appearance to the area (Fig. 3(a) and (b)). Majority of the structures associated with the industrial processes before the decline of the cotton industry in the Derwent Valley such as cotton mills, workshops, and workers' housing have survived, yet, in need of maintenance and repair including the grade-one-listed North Mill, the East Mill, and horseshoe weir as well as the Belper Grammar School built in 1825. In addition, many of the historical farms are under threat as changing modes of agriculture resulted in many farm buildings losing their use.

Considerable economic, social, and environmental change Belper have experienced over the last few decades have resulted in reduced local employment and a shift towards commuting. Due to Amber Valley Borough Council's development strategy allowing

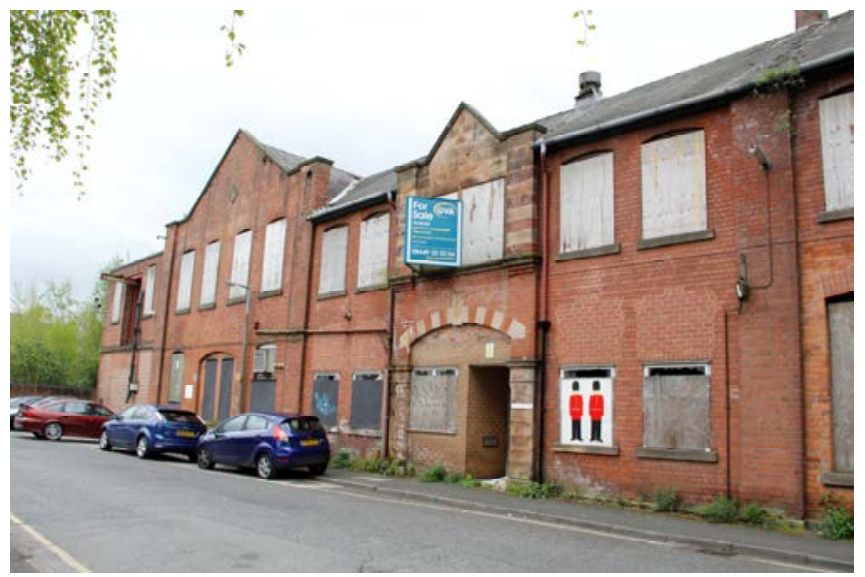

(a)

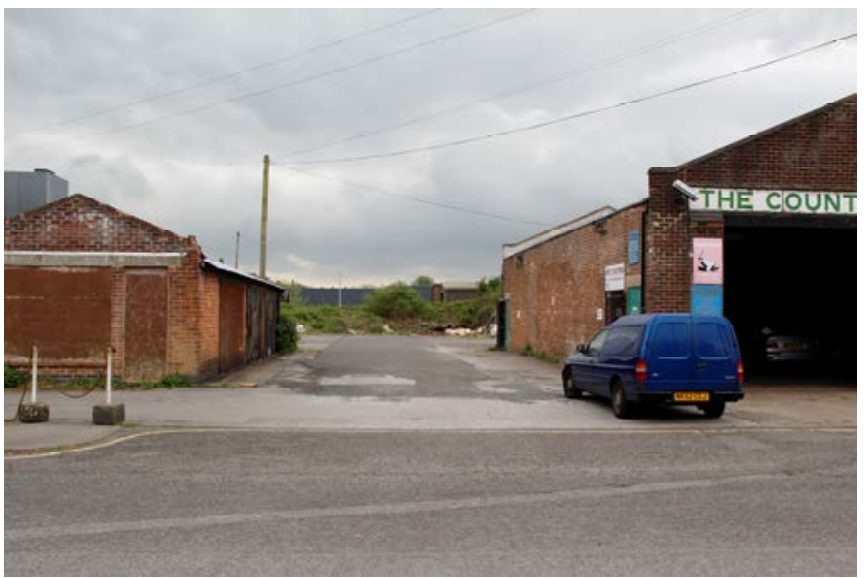

(b)

Figure 3: (a) Thornton's factory at Derwent street, now closed; and (b) One of many demolished light industrial buildings at Derwent street. 
piecemeal changes to the urban fabric of the historic towns through partial plan modifications, the town has seen rapid expansion over the last 30 years with the building of around 2,800 homes since 1983. Almost as many homes were built before 1919. In addition, Amber Valley Borough Council added new homes to its local plan in 2014. Today, the majority of the 26,000 population living in Belper travel to nearby towns or cities for work or leisure, turning the town into a "dormitory". On the other hand, suffering from long-term decline, deprived areas in the town centre have not received investment for many years, which has resulted in building obsolescence and vacant land (Fig. 4). Although the current planning policies set some criteria for development [2], they do not provide guidance on addressing the qualities of the town or setting out a vision as to how it would be managed, and its future development be directed. This is the contradiction of conservation versus preservation, which has long been an issue in planning in Britain [3].

\section{METHODS: READING THE PALIMPSEST}

There exists a significant need to develop innovative design-led strategies for UNESCO World Heritage Sites (WHS) like Belper, which recognise, interpret, and sustain heritage

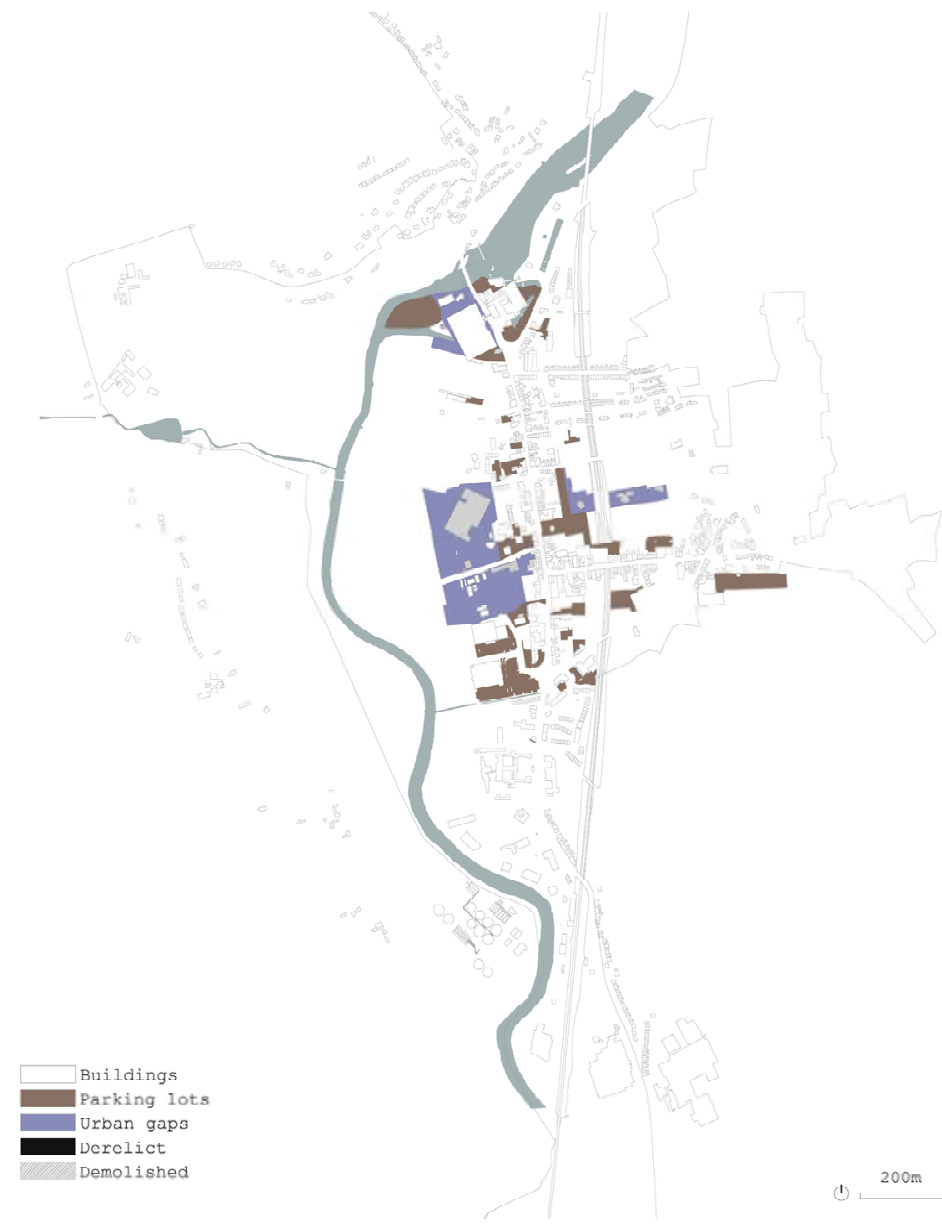

Figure 4: Brownfield sites located in the town centre Belper. 
values that contribute to the identity of the site while also allowing for the development necessary for the support of local communities. Taking context as a starting point and recognising its potential as a conceptual "locus" [4] design can add new layers to the historic urban environment, encouraging change. This leads to a new way of design that considers the sense of place, which embodies town dwellers' years of interaction with the place.

In this respect, it is essential to create a dynamic equilibrium between society, nature, and place where design responds to not only the underlying landscape but also forms and dynamics that are evident in the existing context. Indeed, the etymology of context is "to weave together". Responding to the context, the design weaves diverse elements of the urban fabric into a cohesive whole that is greater than the sum of its parts, making contextual synonymous with compromise. However, the context described here does not refer to either physical structures and built forms of the place or its immediate surroundings and social structures, but to the relationship that exists between them [5].

On the other hand, superimposed programmatic and the contextual design components form a complex structure, whose spatial and conceptual properties also become part of the context. Then, the urban context represents an evolving and uncertain process extending over time rather than as an immutable, pristine object imprisoned by a single moment. Thus, linking past with present and future requires a clear design strategy which will help reveal the relationship existing between the urban conditions and fabric, hence, create a connection between architecture and place.

As Marot suggests with the term sub-urbanism [6], design, through either creating new layers or manipulating the existing ones, can regard the site as a palimpsest to recognise, reinforce, and enhance the distinctive characteristics of the historical context (Fig. 5). The notion of the palimpsest provides a way to excavate the traces of memory and time embedded within multiple overlapping and transitioning layers of the urban fabric.

"Using principles of collage and juxtaposition, history is seen not as linear phenomena, but as layers or discrepancies between a past event (history) and present recalls (memory)" [7]. Palimpsestuous design deals with the phenomenology of place through revealing what is already there while amplifying and exposing the deeper dimensions of it.

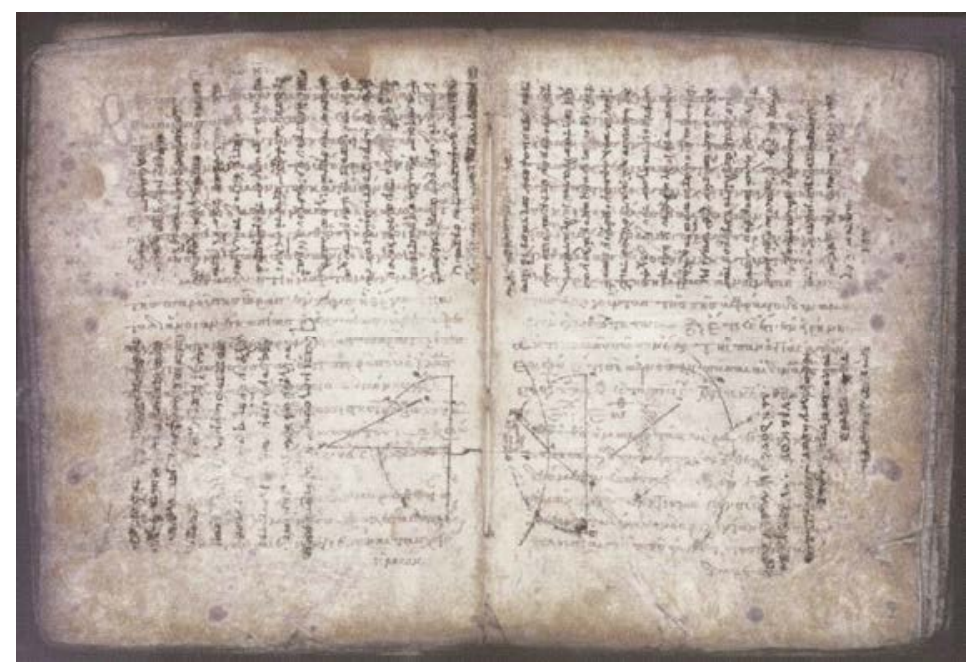

Figure 5: Palimpsest refers to something reused or altered but still bearing visible traces of its earlier form. (Source: Google images, 2018.) 
Thinking of the site as a palimpsest provides a foundation for understanding the physical dynamics of the site and its context. In this regard, the site is interpreted as a heritage place that exists as not only a tangible place in a rural landscape but consist of a range of intangible elements that include history and memory. Understanding the site as an assemblage comprising a multitude of complex and coherent, physical, spatial, and cultural characteristics makes it is possible to recognise and create sequences and potential narratives in the whole. As early as the late 1960s, Graziani and Smithson's "Earthworks" [8] examined excavating as a design strategy. Smithson and Smithson's "as found" [9] approach engaged with "what is there". More recently, Eisenman and Middleton [10] formulated a design strategy which considered the historical layers of a site as defining factors to a design proposal together with current public needs and demands and existing natural conditions.

\section{RESPONDING THE CONTEXT: PALIMPSESTUOUS DESIGN}

Based on a synthesis of concepts drawn from the theories of A. Smithson, P. Smithson, R Smithson, Eisenman, and Marot, this $\mathrm{PhD}$ proposes an innovative approach that seeks to emphasise local characteristics of a place while preserving the residential amenity of it, fully appreciating the context. This includes creating a design-led strategy for the existing historic fabric, which involves a better understanding of the immediate context and design ethics that support successful sustainable development. This is an incremental approach based on uncovering the "deep structure" of place as a source of inspiration for the place-specific design.

The research project approaches Belper's post-industrial landscape as a unifying framework for urban preservation (Fig. 6). As A. Smithson states "The historical built forms were not arrived at by chance or Art, they achieved order through the significant organisation, and the forms have a permanent validity; a secret life, which outlives their direct usefulness" [7].

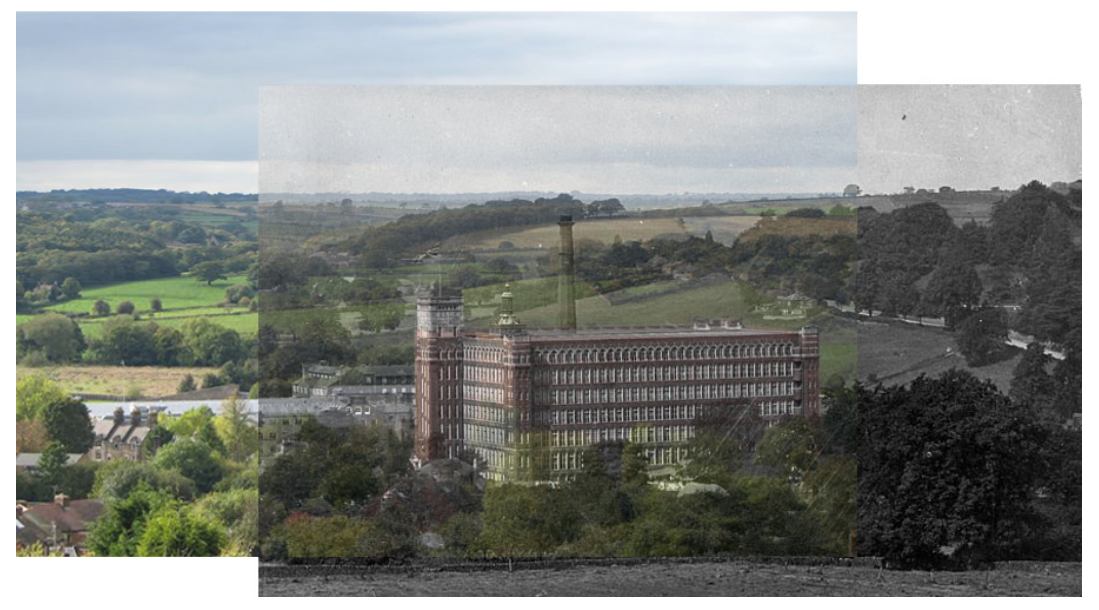

Figure 6: Reading the palimpsest. Collage study for East Mill.

In this respect, the thesis searches for a concrete understanding of Belper's built environment through a discussion of the nature of "place", both natural and manmade recognise its genius loci where the urban life takes place. It studies the town in this means, providing a present-day evaluation of "place". Examining its sense of place, what is added 
or removed, disturbed in the physical, cultural, and social coherence is essential to establish a new coherence.

In order to achieve a sustainable urban environment, the research project suggests a design method that involves both revealing and concealing, engaging different times in history (Fig. 7(a)). This is analogous to R. Smithson's "Earthworks" collaborating with entropy which are about a deliberate engagement of nature's processes of growth and decay - engaging time,

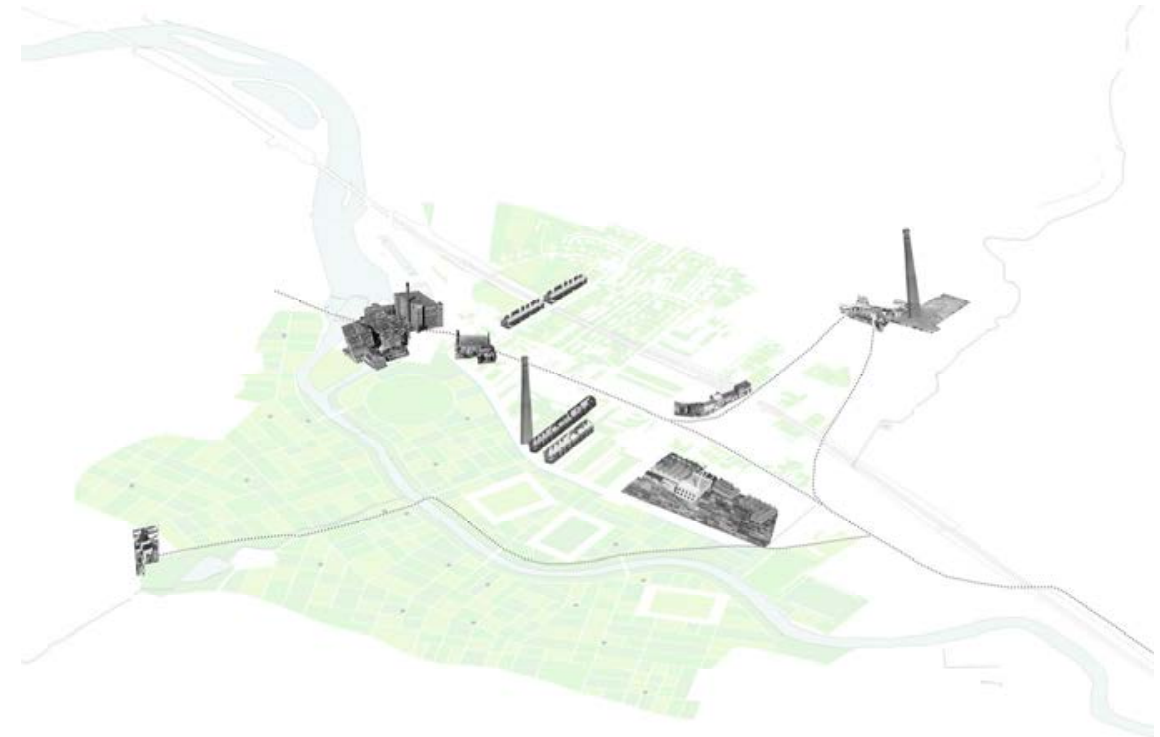

(a)

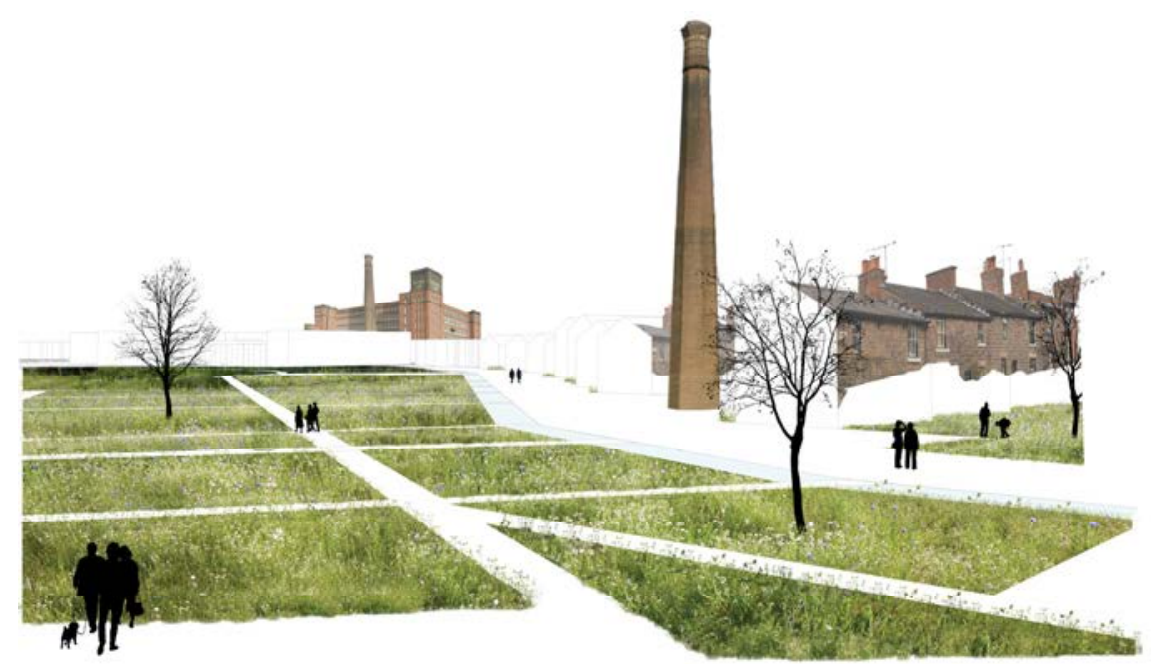

(b)

Figure 7: Mnemonic landscape/(Re)constructed memory. Collage studies created by "borrowing" architectural elements from the past and the present. (a) Belper; and (b) Belper meadows. 
change, and ambiguity which will help tighten fragmented fabric of the town while creating a strong sense of community. The design will respect the established and the individual character of Belper through the use of town's character as an inspiration in new development, prizing context, the street networks, existing buildings, and the respectful study of building types (Fig. 7(b)).

The design following the existing fabric and topography will help weave fragments into the town's historic fabric. This will set the place into a new coherence and make visible a new structure which deals with the town's centre, its edge, its construction, and its landscape. This will provide harmony in the proportions between urban structure and landscape.

Semi-derelict industrial buildings of the Mill complex will be transformed into the social, domestic, and commercial buildings through a successful refurbishment project allowing restoration and conversion for a variety of community uses such as homes, offices, cafes, and shops, while turning the grade-two-listed Mills into a museum, hotel and apartments complex. This will contribute to the setting of the town and the character of the area.

Responding to context, the design will integrate Meadows with the town through adding new layers to the site that will promote a new whole, through the introduction of new uses that will mend the fabric of the place, contributing existing townscape character. The site will be utilised as agricultural land with the introduction of horticulture and apiculture activities with related higher education facilities which will also offer educational programmes to the local young with workshops based on site (Fig. 8).

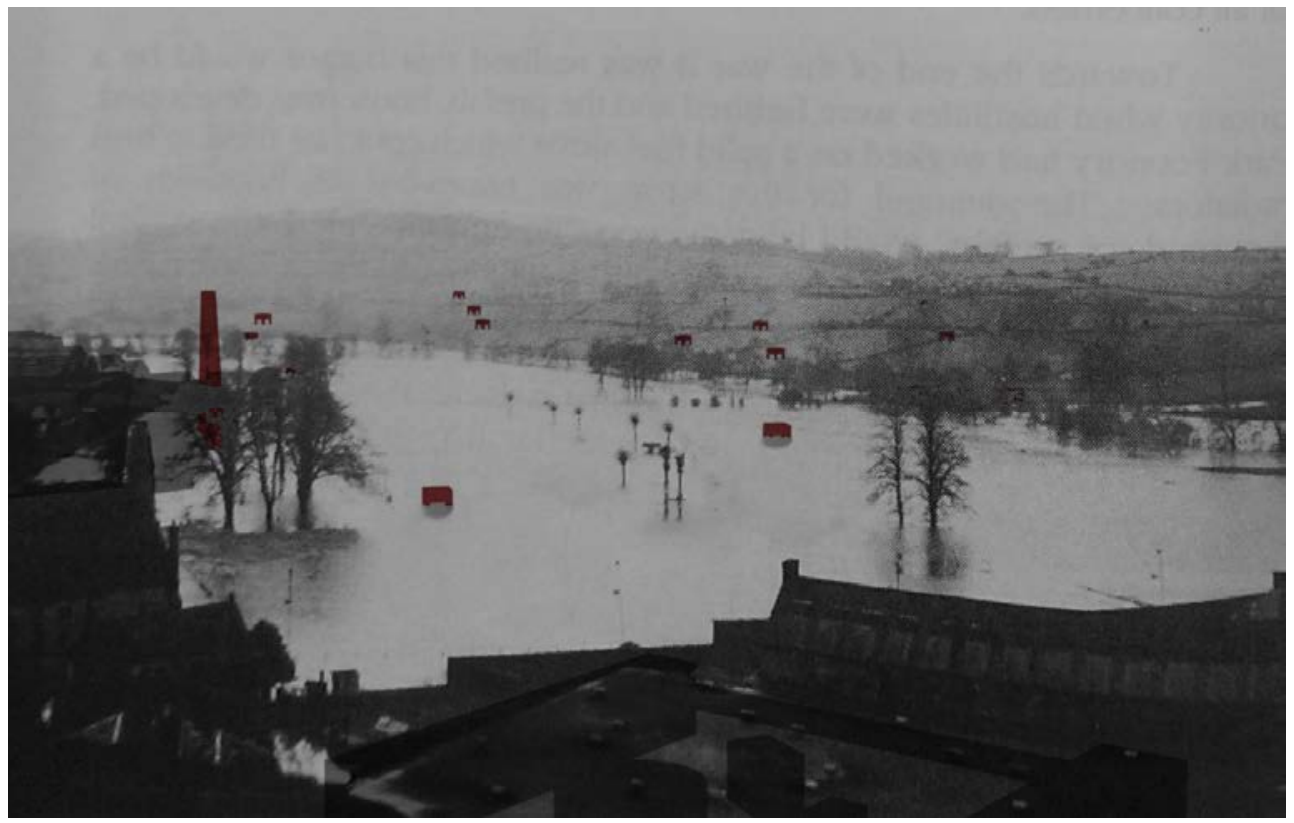

Figure 8: (Re)constructed memory. Flood pavilions proposed for Belper Meadows, which is a high potential flood risk area.

Strengthening the connections between the town centre and the Meadows area both visually and physically will provide opportunities to diversify and enhance the activity being offered in the whole of the town. Meadows' meeting with the River Derwent will become a 
new opportunity for the articulation of the edge between urban space and rural space. This physical and visual link between the River edge and the Meadows edge will allow the rural character of the town to meet its urban character. This will be realised through finding ways of improving access and encouraging the beneficial use of the Meadows. Likewise, routes which link the mills, the town centre, the railway station, the Meadows, and the new development will be defined and designated.

The area's industrial heritage will be sustained through blending light industry with housing, providing more dense and useful mixed-use development with low-cost homes, offices, retail, and workshops in varied sizes. This will not only help transform the areas of derelict land but also respond to the demand for new homes in the region. In addition, the introduction of new manufacturing, research, and higher education facilities will help revive the area, providing considerable employment and training opportunities for the residents. Although regenerating the neglected area is a costlier option in the short term, it will help secure derelict land and restore current infrastructure, creating a thriving new community. This will help stitch the fabric of the town and preserve its character, benefitting future generations.

\section{CONCLUSION: WORKING WITH THE POST-INDUSTRIAL LEGACY}

This research project is significant because it will set the vision and strategic framework to guide future development of Belper for the next 10-20 years and improve spatial and physical relationships between all parts of the town. This will be achieved through promoting and proposing future commercial, industrial, and housing developments embedded into the historic fabric while ensuring that they integrate sustainable environmental and transport strategies.

The contribution to knowledge is the design and development of a research-led strategic framework for the future development of World Heritage Sites that develops current theories and methods. It is a unique combination of alternative urban theories, critical interpretation of heritage rules/requirements and a practice-led approach. For the disciplines and practices of architecture and town design, this research offers a way to reconsider the design in heritage sites by addressing questions of transformation and preservation and going beyond the commonly held view of heritage assets as untouchable relics. Hence, it provides a rethinking of conservation, by developing a critical approach for the analysis and design of the intervention, informed by the shared international principles and the specific nature and context of the historic building to be conserved.

\section{ACKNOWLEDGEMENTS}

This research has been funded with an award from the London Doctoral Design Centre, the Arts and Humanities Research Council (AHRC).

I would like to thank the anonymous reviewers for their valuable suggestions for improvement, and Dr Alexandra Stara for revising the text of the paper.

\section{REFERENCES}

[1] UNESCO, Derwent Valley Mills: Outstanding universal value, 2001. http://whc.unesco.org/en/list/1030. Accessed on: 23 Jun. 2015.

[2] Amber Valley Borough Council (AVBC), Supplementary planning document and development brief for land between the A6 and the River Derwent, Belper, Derby, 2012.

[3] Larkham, P.J., Conservation and the City, Routledge: London and New York, p. 251, 1996. 
[4] Rossi, A., The Architecture of the City, MIT Press: New York, p. 131, 1991.

[5] Jones, A., Contextual form: A journey from here to there. Encounters between Here and There Exhibition Catalogue, The Architecture Foundation: London, pp. 18-20, 2001.

[6] Marot, S., Sub-Urbanism and the Art of Memory, Architectural Associations: London, 2003.

[7] Kirkwood, N., Manufactured Sites: Rethinking the Post-Industrial Landscape, Spon: London, p. 129, 2001.

[8] Graziani, R. \& Smithson, R., Robert Smithson and the American Landscape, Cambridge University Press: Cambridge, 2004.

[9] Smithson, A. \& Smithson, P., Ordinariness and Light: Urban Theories 1952-1960 and Their Application in a Building Project 1963-1970, MIT Press: Cambridge, 1970.

[10] Eisenman, P. \& Middleton, R., Architecture in a mediated environment. The Idea of the City, eds P. Eisenman \& R. Middleton, Architectural Associations: London, p. 61, 1996. 